\title{
Detección de Enterobacteriaceae en huevos frescos de gallina para el consumo humano en la ciudad de Valledupar, Cesar (Colombia)
}

\author{
Álvaro Vicente Araujo-Guerra, M.Sc. ${ }_{1}^{*}$, Pedro José Fragoso-Castilla, Ph.D. ${ }_{1}$, \\ Alex Efraín Peña-Guillin, Microb., Álvaro Pineda-Quintero, Zoot. ${ }_{2}$, \\ Jesús Federico Mejía-Arbeláez, Zoot.
}

Facultad de Ciencias de la Salud, Universidad Popular del Cesar, Valledupar, Cesar ${ }_{2}$ Escuela de Ciencias Agrícolas, Pecuarias y del Medio Ambiente, Universidad, Nacional Abierta y a Distancia, Valledupar, Cesar (Colombia).

Recibido: 29 de junio del 2018

Aprobado: 2 de agosto de 2018

*Autor de correspondencia: Álvaro Vicente Araujo Guerra, Escuela de Ciencias Agrícolas, Pecuarias y del Medio Ambiente, Universidad Nacional Abierta y a Distancia, Valledupar, Cesar, Colombia. Calle 18 n. ${ }^{\circ}$ 9-63, Valledupar. Tel.: 3003432834. Correo electrónico: alvaroaraujo@unicesar.edu.co

Cómo citar este artículo: Araujo-Guerra ÁV, Fragoso-Castilla PJ, Peña-Guillin AE, Pineda-Quintero Á, Mejía-Arbeláez JF. Detección de Enterobacteriaceae en huevos frescos de gallina para el consumo humano en la ciudad de Valledupar, Cesar (Colombia). Spei Domus. 2017; 13(26-27):1-7. doi: https://doi.org/10.16925/2382-4247.2017.01.03

Resumen. Introducción: la familia Enterobacteriaceae es el grupo más grande y heterogéneo de bacilos gramnegativos, muchos de ellos de importancia en salud pública, asociados entre otros al consumo de huevos frescos, aún de aquellos con cáscara indemne y limpia Metodología: fueron obtenidos por muestreo 200 huevos en 10 expendios comerciales en la ciudad de Valledupar, Cesar (Colombia), a los cuales se les estudió la cáscara y las yemas, mediante protocolo de preenriquecimiento, enriquecimiento selectivo y, luego, medio selectivo diferencial para determinar la presencia de enterobacterias. Resultados: se determinó la presencia en cáscara y yemas de enterobacterias en un 31,0 \% de los huevos, así como 15,5\% con contaminación con otros microorganismos. Se comprobó también la presencia del hongo Aspergillus fumigatus. Conclusiones: los resultados demuestran la presencia de agentes patógenos en los huevos comercializados en el área estudiada, y la consecuente necesidad de intervenir para proteger la salud de los consumidores. Se recomienda la intervención de los actores de salud pública, para que intervengan y adelanten investigaciones para conocer potenciales riesgos para la salud, lo mismo que en la documentación de casos asociados al consumo de estos huevos.

Palabras clave: alimentos contaminados, microbiología, salud pública. 


\section{Detection of Enterobacteriaceae in fresh chicken eggs for human consumption in the city of Valledupar, Cesar (Colombia)}

Summary. Introduction: the Enterobacteriaceae family is the largest and most heterogeneous group of gram-negative bacilli, many of them of public health importance, associated among others with the consumption of fresh eggs, even those with intact and clean skin. Methodology: 200 eggs were obtained by sampling at 10 commercial outlets in the city of Valledupar, Cesar (Colombia), of which the shell and yolks were studied using a pre-enrichment protocol, selective enrichment and, therefore, a selective medium. differential to determine the presence of enterobacteria. Results: the presence of enterobacteria in the shell and yolks was determined in $31 \%$ of the eggs, as well as $15.5 \%$ with contamination with other microorganisms. The presence of the fungus Aspergillus fumigatus was also proven. Conclusions: the results demonstrate the presence of pathogenic agents in eggs marketed in the studied area, and the consequent need to intervene to protect consumers' health. It is recommended that public health agents take action to intervene and conduct research in order to find out about potential health risks, as well as document cases associated with the consumption of these eggs.

Keywords: contaminated food, microbiology, public health.

\section{Detecção de Enterobacteriaceae em ovos frescos de galinha para o consumo humano na cidade de Valledupar, Cesar (Colômbia)}

Resumo. Introdução: a família Enterobacteriaceae é o maior e mais heterogêneo grupo de bacilos gram-negativos, muitos deles de importância em saúde pública, associados entre outros ao consumo de ovos frescos, mesmo daqueles com casca intacta e limpa. Metodologia: foram obtidos por amostragem 200 ovos em 10 pontos de venda comerciais na cidade de Valledupar, Cesar (Colômbia), dos quais foram estudadas a casca e as gemas por meio de protocolo de pré-enriquecimento, enriquecimento seletivo e, logo, meio seletivo diferencial para determinar a presença de enterobactérias. Resultados: determinou-se a presença de enterobactérias na casca e nas gemas em $31 \%$ dos ovos, bem como 15,5 \% com contaminação com outros microrganismos. Comprovou-se também a presença de fungo Aspergillus fumigatus. Conclusões: os resultados demonstram a presença de agentes patogênicos nos ovos comercializados na área estudada, e a consequente necessidade de intervir para proteger a saúde dos consumidores. Recomenda-se a ação dos agentes de saúde pública para que intervenham e realizem pesquisas com o objetivo de conhecer potenciais riscos para a saúde, bem como documentem casos associados ao consumo desses ovos.

Palavras-chave: alimentos contaminados, microbiologia, saúde pública. 


\section{Introducción}

Los agentes asociados a las enfermedades transmitidas por los alimentos contaminados tienen una importancia relevante y frecuentemente son responsables de brotes de enfermedades [1]. Se reporta una amplia variedad de enterobacterias como agentes patógenos para humanos, animales domésticos y silvestres [2]. Así mismo hay una gran cantidad de géneros bioquímica y genéticamente relacionados. Existen más de 2.500 serovariedades de salmonela, de las cuales unas 250 se han aislado de las aves de corral, siendo 40 de ellas las más comúnmente encontradas. Las enterobacterias causan alrededor del $57 \%$ de las toxiinfecciones alimentarias humanas y entre ellas, los géneros salmonela, campilobacter y listeria, de enorme importancia en salud pública y especialmente relacionada con el subsector avícola [3].

El incremento de la presencia de Salmonella spp. en productos procedentes de actividad avícola se ha agudizado con la globalización, debido a que el consumo de carne de pollo y huevos ha aumentado en todo el mundo [4]. Sin embargo, los datos disponibles no permiten establecer los posibles niveles de contaminación de los huevos de gallina y en especial con relación a los del género Enterobacteriaceae [5]. Además, dos factores además de los mencionados se asocian a la contaminación de los huevos: los deficientes procesos de cocción y la contaminación cruzada con materias primas crudas contaminadas [6].

Así mismo, la cáscara del huevo puede hacerse permeable, lo que facilita el ingreso de aire y hongos que colonizan su interior [7], propicia su contaminación y crea una condición favorable para su crecimiento y expansión, que lleva a la putrefacción. Este proceso podría retardarse mediante almacenamiento a baja temperatura o por tratamiento de la cámara para cerrar los poros [8].

En la fase productiva primaria se deben extremar los cuidados y medidas de bioseguridad, de tal manera que se garanticen medidas integrales de prevención y control en términos de medidas sanitarias para asegurar la calidad e inocuidad del producto [11]. Epidemiológicamente, el control de microorganismos en la cadena avícola es de vital importancia [12], porque al reducir la prevalencia de Enterobacteriaceae y hongos en los huevos de gallinas, se disminuyen los riesgos para la salud humana, ya que la mayoría de ellos son causantes de enfermedades zoonóticas, y es necesario que el personal a cargo se enfoque en controlar y disminuir riesgos en la planta de producción [13].

El contenido interno de los huevos recién puestos es generalmente estéril [14]. Al momento de la ovoposición, los huevos tienen cierto grado de contaminación en la superficie debido al paso a través de la cloaca de la gallina [15]. No obstante, de 8 a 10 días después de la puesta se pueden encontrar gran cantidad de microorganismos en su exterior, que bajo condiciones apropiadas pueden penetrar en los huevos, crecer en su interior y alterarlos [16]. Por transmisión vertical los microorganismos entran en los huevos desde los ovarios o el tejido del oviducto antes de la formación de la cáscara [17]. El hallazgo de Enterobacteriaceae en la yema del huevo y no en su superficie, resulta de la contaminación transovárica del huevo [18]. Así, la contaminación de huevos con agentes de la familia Enterobacteriaceae son un riesgo y una importante amenaza para la salud pública a nivel mundial [19].

Dentro de diversas estrategias de la salud pública orientadas a la prevención y el control de enfermedades, el diagnóstico, monitoreo e identificación de riesgos actuales y potenciales son actividades deseables, y con este propósito se realizó esta investigación con el interés de detectar la presencia de Enterobacteriaceae en huevos frescos para consumo humano, en diferentes expendios de Valledupar, Cesar.

\section{Materiales y métodos}

\section{Toma y transporte de las muestras}

Para la toma de muestras se hizo una selección completamente al azar hasta completar el número total de expendios, que fueron 10 , y se realizó muestreo durante 3 semanas en cada uno de ellos. En cada expendio se tomaron 20 huevos y se registró su ubicación, estructura física, vigencia de registro sanitario y número de trabajadores. Los huevos fueron manipulados con guantes estériles con el fin de evitar una contaminación cruzada y se rotularon uno por uno con un código; los huevos se depositaron en un termo a $4-8^{\circ} \mathrm{C}$ para su respectivo transporte al laboratorio de Microbiología de la Universidad Popular del Cesar en Valledupar. El tamaño de la muestra se estimó sobre un nivel de confianza de 
un $95 \%$, con una prevalencia esperada del $3 \%$ y un error menor del $5 \%$.

\section{Procesamiento de las muestras}

El procesamiento de las muestras tanto para la cáscara como para la yema de huevo se hizo con sujeción a la Norma Técnica Colombiana 4574 (Icontec 2007), que consiste en 4 etapas:

\section{Preenriquecimiento en medio líquido no selectivo}

La cáscara fue cortada con pinzas de disección estériles colocadas en cajas de Petri para su pesaje, hasta obtener 25 gramos de la muestra, se introdujo en un mortero estéril para macerarla. Posteriormente, los 25 gramos de muestra macerada fueron transferidos en 225 mililitros de agua peptonada tamponada contenida en frascos de tapa ancha, e incubados a $37{ }^{\circ} \mathrm{C} \pm 1{ }^{\circ} \mathrm{C}$ durante 18 $\mathrm{h}+/ 2$ horas.

\section{Enriquecimiento en medio líquido selectivo}

Después de 18 horas de incubación en los frascos con agua peptonada, se extrajeron 0,1 mililitros para inocularlo en 10 mililitros de caldo Rappaport Vassiliadis (medio RVs). Los tubos con caldo Rappaport Vassiliadis se incubaron a $41,5^{\circ} \mathrm{C} \pm 1,0$ ${ }^{\circ} \mathrm{C}$ durante $24 \mathrm{~h} \pm 3$ horas.

\section{Inoculación en medio selectivo y diferencial}

Transcurrido el tiempo de incubación se extrajeron los tubos con el caldo Rvs, este se inoculó en placas de agar Xilosa Lisina Desoxicolato (XLD) e incubó a $37^{\circ} \mathrm{C} \pm 1^{\circ} \mathrm{C}$, durante las $24 \pm 3$ horas, momento en el que se tomaron registraron los resultados.

\section{Selección de colonias para su confirmación}

Cuando en el medio selectivo y diferencial se desarrollaron colonias con centro negro, grande, brillante o completamente negro en las placas de agar XLD, se consideraron sugestivas de ser Salmonella spp.; entonces fueron seleccionadas e inoculadas en placas de agar nutritivo e incubadas a $37{ }^{\circ} \mathrm{C}$ durante 24 horas.

\section{Confirmación por pruebas bioquímicas}

Para la identificación fenotípica se inoculó una batería de pruebas bioquímicas: agar citrato Simmons, agar de hierro y lisina (LIA), sulfuro, indol, movilidad (SIM), urea, Voges - Proskauer (VP), agar de hierro y triple azúcar (TSI). El agregado de pruebas bioquímicas se incubó a $37^{\circ} \mathrm{C}$ durante $24 \pm 3 \mathrm{~h}$. Una vez finalizado el tiempo de incubación a las 24 horas se buscó mediante lectura la presencia o ausencia de enterobacterias, aquellas sin detección, fueron mantenidas 24 horas más para una nueva lectura.

\section{Resultados y discusión}

De las 200 unidades evaluadas se encontró que 31 huevos procedentes de los 10 expendios tenían algún tipo de contaminación bacteriana; así en el $15,5 \%$ de las unidades se confirmó la presencia de algún tipo de microorganismo, bien en la cáscara: 29 huevos, o en la yema: 2 huevos (tabla 1). Este resultado es menor al reportado por Leyva et al. [20], quienes encontraron positividad a enterobacterias en el 17,57 \% de las muestras de huevos, en un estudio realizado en Cuba. En otro estudio este valor fue del $26 \%$, con reportes de incremento en la detección positiva de un $78,8 \%$ de huevos procedentes de 5 granjas avícolas [21].

Tabla 1. Huevos positivos y participación porcentual de Enterobacteriaceae en expendios comercializados en Valledupar, Cesar (Colombia)

\begin{tabular}{cccc}
\hline $\begin{array}{c}\mathrm{N}^{\circ} \\
\text { expendio }\end{array}$ & $\begin{array}{c}\mathrm{N}^{\circ} \text { de huevos } \\
\text { muestreados }\end{array}$ & $\begin{array}{c}\mathrm{N}^{\circ} \text { huevos } \\
\text { positivos }\end{array}$ & $\begin{array}{c}\text { Porcentaje } \\
\text { positivos }\end{array}$ \\
\hline 1 & 20 & 0 & $0,0 \%$ \\
2 & 20 & 2 & $10,0 \%$ \\
3 & 20 & 4 & $20,0 \%$ \\
4 & 20 & 3 & $15,0 \%$ \\
5 & 20 & 0 & $0,0 \%$ \\
6 & 20 & 1 & $5,0 \%$ \\
7 & 20 & 4 & $20,0 \%$ \\
8 & 20 & 3 & $15,0 \%$ \\
9 & 20 & 6 & $30,0 \%$ \\
10 & 20 & 8 & $40,0 \%$ \\
\hline
\end{tabular}

Fuente: elaboración propia 
En los 200 huevos analizados se encontró contaminación bacteriana por enterobacterias. En la figura 1, se observa la distribución de los hallazgos de enterobacterias según su presencia en cáscara o yema. Se aprecia que el $95 \%$ de ellas fue en la cáscara, mientras que el $5 \%$, en las yemas. Este hallazgo es diferente al de un estudio realizado en Cuba con $12 \%$ de contaminación en cáscaras y $7,1 \%$ en yemas [22]. Por su parte otro reporte proveniente de Ciudad de México evidenció una distribución del $13 \%$ y $67 \%$ de Enterobacteriaceae en cáscara y yema respectivamente [18].

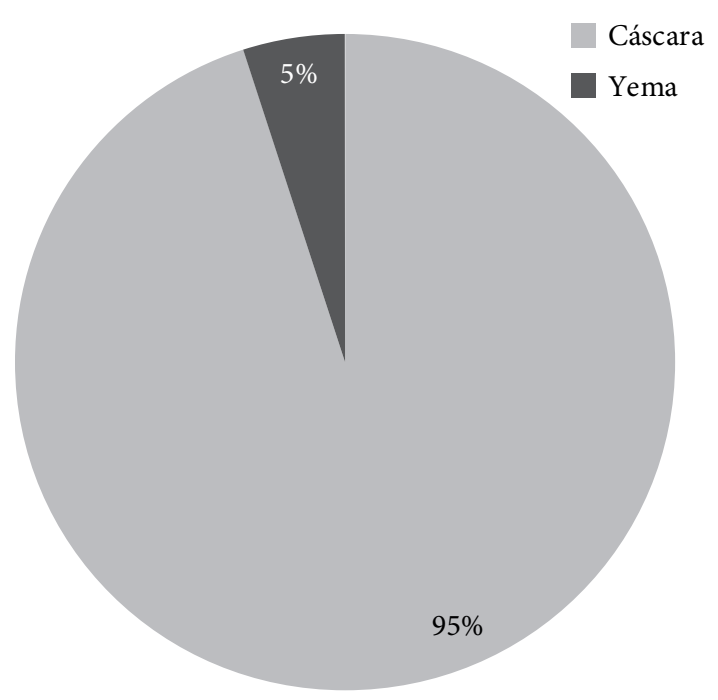

Figura 1. Enterobacteriaceae en huevos comercializados en expendios de Valledupar, Cesar (Colombia)

Fuente: elaboración propia

No se encontró salmonela spp. en las muestras analizadas. Sin embargo, es conveniente no asumir que esta ausencia de detección exime a los consumidores de exposición al riesgo. Por ejemplo, en una central clasificadora de Castellón, Madrid, con un reporte microbiológico del $0,26 \%$, se confirmaron brotes epidémicos de toxiinfección alimentaria por salmonela asociados al consumo de huevos de gallina [23].

Respecto a aislamientos de Salmonella spp. en huevos, los datos obtenidos varían considerablemente [24], sin embargo, en la mayoría de los estudios la detectan en este alimento, lo que confirma su circulación en las cadenas de producción avícola de varios países. En México la Salmonella spp. se detectó en el 0,25\% de los huevos muestreados [25], mientras que en Brasil se aisló a partir del $2 \%$ de las muestras de huevo procesadas [26]. En Cuba la Salmonella spp. fue aislada de 2 muestras de cáscara correspondientes al 0,6\% del total de muestras [27], resultados que son similares a los informados por otros investigadores, quienes obtuvieron el $1 \%$ de positividad para Salmonella spp, en cáscara de huevo, pero no la aislaron del interior [15]. Así mismo, en Tunja, Colombia, se identificó la presencia de salmonela en cuatro huevos correspondientes al $3 \%$ del total de muestras de 128 huevos provenientes de 5 avícolas de diferentes zonas de la ciudad y de un vendedor independiente de la plaza de mercado del sur de la misma ciudad [28].

Algunos estudios sugieren la contaminación de los huevos dentro del tracto reproductivo, y que algunos factores dentro de los huevos pueden controlar la salmonela antes de su postura [29]. Los datos muestran que los huevos están expuestos a infecciones descendentes de tejido ovárico colonizado, infecciones ascendentes de tejidos vaginales y cloacales colonizados, e infecciones laterales de tejidos de oviducto superior colonizados [30].

Finalmente, la detección de Aspergillus fumigatus en el interior de un huevo en forma circunstancial muestra otros riesgos para la salud pública (figura 2). Esta evidencia de la presencia de este hongo en huevos de gallinas para consumo humano se reporta por primera vez en este tipo de estudios, ya que no existe información a nivel local ni regional. Las esporas de Aspergillus sobreviven y crecen en una amplia gama de condiciones, pero sobre todo en materia orgánica como la yema de huevo, cajas de cartón y madera [31]. Igualmente, el micelio de Aspergillus spp. es similar a la de la mayoría de los otros hongos. Está bien desarrollado, ramificado, hialino y septado. El micelio puede producir grandes cantidades de enzimas, y algunas producen micotoxinas. La fase micelial de Aspergillus spp. se caracteriza por un crecimiento vigoroso y una abundante producción de conidios [32].

\section{Conclusiones}

Se detectaron enterobacterias en el $100 \%$ de las muestras, tanto en cáscara como en yemas, lo que pone de presente el riesgo sanitario por consumo de huevos. Por otra parte, no se encontró Salmonella spp., como frecuentemente ocurre en este tipo de estudios. Como un hecho interesante 
y de destacar, con el interés de futuras investigaciones e intervenciones, se reporta el primer hallazgo de un hongo filamentoso dentro de un huevo proveniente de uno de los expendios de Valledupar. Estos hallazgos, en su conjunto, demandan mayores investigaciones y diferentes abordajes metodológicos que consideren en sus técnicas la diversidad de agentes de importancia en salud pública potencialmente presentes en los huevos frescos para el consumo humano.

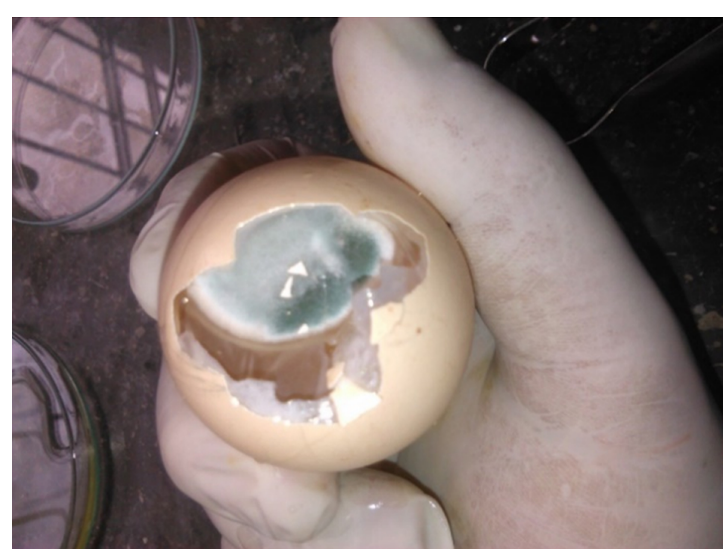

Figura 2. Presencia del hongo Aspergillus fumigatus en el interior de un huevo de gallina para consumo humano en expendio de Valledupar, Cesar (Colombia). Nótese la película algodonosa en la superficie de color verde grisácea

Fuente: elaboración propia

\section{Referencias}

[1] Sánchez, A, Minor, H; Barrientos, R; Dublan, O. Foodsafety and antimicrobial resistance an approach to the genus Salmonella spp. Journal of Biosciences and Medicines. 2017 en.;5(2):55-71.

[2] Pachón, D. Aislamiento, identificación y serotipificación de enterobacterias del género Salmonella en una población de Crocodylus intermedius y testudinos mantenidos en cautiverio en la estación de biología tropical Roberto Franco e.b.t.r.b. [Tesis de pregrado]. [Villavicencio, Colombia]: Universidad Nacional de Colombia; 2009.

[3] Terzolo, H. Salmonelosis: Una visión integral. En: Calidad y Seguridad Agroalimentaria 2014. Un desafío interdisciplinario. Actas de las IV Jornadas Bahienses de Seguridad Alimentaria, Bahía Blanca: Edinus; 2015, Argentina. p. 157-176.
[4] Soria, A. Presencia de Salmonella y características físicas de huevos destinados a consumo humano [Tesis de maestría]. Santa Fe: Universidad Nacional del Litoral; 2014. 223p.

[5] Sánchez-Mora MJ. Determinación de la prevalencia de enterobacterias del género Salmonella spp. en huevos frescos de gallina de empresas avícolas de la provincia del Tungurahua. [Trabajo de pregrado]. [Quito, Ecuador]: UCE; 2013.

[6] Toro-Sierra CA. Estandarización del proceso de producción del pollo y la carne con verduras usados para los productos de hojaldre que se elaboran y comercializan en la Panaderia Novapan. [Tesis doctoral]. [Antioquia, Colombia]: Corporación Universitaria Lasallista; 2012.

[7] De Reu K, Grijspeerdt K, Messens W, Heyndrickx M, Uyttendaele M, Debevere J, et al. Eggshell factors influencing eggshell penetration and whole egg contamination by different bacteria, including Salmonella enteritidis. Int J Food Microbiol. 2006 dec.; 112(3):253-60.

[8] Suárez C, Mantilla R. Presencia de Salmonella serovariedad enteritidis en productos de origen avícola y su repercusión en salud pública. IATREIA. 2000; 13(4):237-45.

[9] Carrillo L. Los hongos de los alimentos y forrajes. Salta, Argentina: Universidad Nacional de Salta; 2003. 118 p.

[10] Tomczyk Ł, Szablewski T, Stuper-Szablewska K, Nowaczewski S, Cegielska-Radziejewska R. The influence of the conditions of acquisition and storage of table eggs on changes in their quality and the presence of mycobiota and Fusarium mycotoxins. Poultry Science. 2019 jul.; 98(7): 2964-71. doi: 10.3382/ ps/pez156.

[11] Álvarez ML. El sector avícola colombiano. Un caso de aplicación del concepto de competitividad. Revista Unisangil Empresarial. 2013; 6:46-70.

[12] Jaimes-Olaya JA, Gómez-Ramírez AP, Álvarez-Espejo DCM, Soler-Tovar D, Romero-Prada JR, et al. The infectious diseases and their importance in the poultry industry. Rev. Med. Vet. 2010, (20):49-61.

[13] Díaz T, Caballero A, Díaz J, Cardona M, Morejón P, Sánchez Y. Estudio, control y prevención de las ETA: infección e intoxicación por alimentos. Instituto de Nutrición e Higiene de los Alimentos, Cuba. Rev. Soc. Ven. Microbiol. 2006; 26:95-100.

[14] Acosta-Vargas RF. Caracterización de salmonella (Salmonella spp.) en huevos frescos de gallinas mediante la utilización del sistema microgen gn a en la parroquia Cotaló [Tesis de pregrado]. [Ambato, Ecuador]: Universidad Técnica de Ambato; 2016. $58 \mathrm{p}$. 
[15] Rincón P, Vargas C, Ramírez Y. Búsqueda de Salmonella spp. en huevos para consumo humano comercializados en la ciudad de Tunja: estudio preliminar. Revista Proyección Universitaria. 2011 jun.; 2:34-48.

[16] Backer C, Goff J, Timoney J. Prevalence of Salmonella on eggs from poultry farms in New York State. Poult Sci, 1980 feb.; 59(2):289-92. doi: 10.3382/ ps.0590289

[17] FOA-OMS. Evaluaciones de riesgos en salmonella en huevos y pollos. 2002; Cap. 1. Evaluaciones de riesgos en salmonella en huevos y pollos. pp 7-10. Disponible en: https://www.who.int/foodsafety/publications/micro/mra_fruitveges/en/

[18] Mancera A, Navarretea J, Ontiveros M. Identificación de Salmonella enteritidis en huevo para consumo en la ciudad de México. Téc Pecu Méx; 2005 en.; 43(2):229-37.

[19] Ramírez AR, Quintanilla M. Detección de enterobacterias en huevos procedentes de 5 granjas avícolas en occidente de Nicaragua. Octubre-noviembre 2013. [Tesis de pregrado]. [León. Nicaragua]: Universidad Nacional Autónoma de Nicaragua; 2016. $76 \mathrm{p}$.

[20] Leyva V, Valdés E, Cisneros E, Pérez O. Determinación de salmonella y enterobacterias totales en huevos frescos de gallina. Rev Cubana Aliment Nutr; 1996; 10(2):83-6.

[21] Vejar. O. Caracterización de microorganismos detectados en el interior del huevo de crianza de traspatio a la venta en el Mercado central de la Cuidad de Chillán-Chile. [Tesis de Pregrado]. [Concepción, Chile]: Universidad de Concepción; 2011.

[22] De La Osa M, Olmo N, Botas M, Menezet A, Pérez F. Estudio bacteriológico y comercial en huevos de gallina. Revista de tecnología e higiene de los alimentos. 1988; 88:41-7.

[23] Carbó-Malonda RM, Miralles.Espí MT, Sanz-Bou R, Mañas-Gimeno F, Guiral- Rodrigo S, Pérez-Pérez E. Brote de toxiinfección alimentaria por salmonella entérica en un establecimiento de restauración colectiva. Revista Española de Salud Pública. 2005 en.; 79(1):47-57.
[24] Castañeda-Salazar R, Pulido-Villamarín A, Mendoza-Gómez MF, Carrascal-Camacho AK, Sandoval-Rojas KL. Detección e identificación de Salmonella spp. en huevos para consumo humano, provenientes de diferentes localidades de Bogotá, Colombia, 2015. Infect; 2017; 21(3):154-9.

[25] Mancera A, Navarretea, J.; Ontiveros, M. Identificación de Salmonella enteritidis en huevo para consumo en la ciudad de México. Téc Pecu Méx; 2005. 43(2):229-37. Disponible en: https://www.redalyc. org/pdf/613/61343209.pdf

[26] Gama N, Berchieri R, Fernández A. Occurrence of Salmonella $s p$ in laying hens. Rev Bras Cienc Avic; 2003; 5(1):15-21.

[27] Leyva V, Valdés E, Cisneros E, Pérez O. Determinación de Salmonella y enterobacterias totales en huevos frescos de gallina. Rev Cubana Aliment Nutr. 1996; 10(2):83-86.

[28] De La Osa M, Olmo N, Botas M, Menezet A, Pérez, F. Estudio bacteriológico y comercial en huevos de gallina. Rev de tecnología e higiene de los alimentos 1988, 88: 41-47.

[29] Méndez IA, Badillo CA, Parra GO, Faccini ÁA. Caracterización microbiológica de Salmonella en alimentos de venta callejera en un sector universitario de Bogotá, Colombia. Julio a octubre de 2010. Revista Médicas UIS. 2011 mzo.;24(1):23-9.

[30] Timoney JF, Shivaprasad HL, Baker RC, Rowe B. Egg transmission after infection of hens with Salmonella enteritidis phage type 4. Vet Rec. 1989 dic; 125(24):600-1.

[31] Dinev I. Enfermedades de las aves. El Sitio Avícola. [Internet]. 2014. Disponible en: http://www.elsitioavicola.com/publications/6/enfermedades-de-las aves/

[32]. Malcolm D, William H. Aspergillus. Infections caused by non-Candida, non-Cryptococcus yeasts. En: Anaissie EJ, McGinnis MR, Pfaller MA, editors. Clinical Mycology. $2^{\mathrm{a}}$ ed. Londres: Churchill Livingstone; 2009. p. 251-270. 